\title{
The stress analytical comparison on crankshaft manufactured by structural steel and ductile iron based on SOLIDWORS and ANSYSWORKBENCH
}

\author{
Cai Han-ming ${ }^{1}$ Wang Peng-fei ${ }^{2}$ Xi Da-Wei $^{3}$ \\ College of mechanical and electrical engineering of Qingdao University of Science and Technology, \\ Qingdao 266042, China
}

Keywords: crankshaft; analysis of stress; materials; Solid Works; ANSYSWORKBENCH

\begin{abstract}
Firstly, we created the 3D model of crankshaft used HT-A150 engine in the tractor. Secondly, we cumulated the loads of the crankshaft when it was working at the most dangerous state. At last, we conducted stress and strain simulations about the crankshaft manufactured by two sorts of materials by analysis system. So, we drew an important conclusion. This conclusion will provide necessary references for us at the aspect selecting materials.
\end{abstract}

\section{Introduction}

Crankshaft performance directly affects the quality and service life of automobile engine. Crankshaft bears all output power of engine and bending moment and torsion moment under changing the direction, also has experienced tremendous wear in high speed operation. So, it easily raise torsion fatigue damage and bending fatigue failure in the stress concentration region [1].So we should accurately identify the stress and strain distribution of the crankshaft in the work process. [1] In order to avoid excessive stress concentration and then meet "the principles of equal strength" of the mechanical design. We should not only consider the material having high rigidity, fatigue strength and good wear resistance, but also think the part working in the actual situation. In order to achieve the optimization design, we should consider all kinds of factors, when we select the material of crankshaft .So, we conducted the stress and strain analytical comparison on crankshaft manufactured by structural steel and ductile iron based on AnsysWorkbench. Thus we obtained the reasonable analysis data, and provide the necessary reference for later sorting.[4]

\section{Introduction of structural steel and ductile iron [7]}

\subsection{The introduction of carbon structural steel}

Carbon steel is usually the alloy of iron and carbon. Carbon content is lower than $1.35 \%$ or contains a small amount of silicon, manganese, phosphorus, sulfur (within the specified scope) and other trace residual elements also are known as carbon steel. [5] Carbon steel is the most basic material used the earliest, the largest amount in modern industry. With the carbon steel varieties increased and quality improved, its application scope is way wider.

\subsection{The introduction of ductile cast iron}

Ductile cast iron is a kind of high strength cast iron material developed in the fifty's of last century. Its comprehensive performance is closed to steel. According to the existing form of carbon, it is divided into: cast iron and ductile iron .et. [5] Ductile cast iron is acquired by ball and inoculation. So, it has good mechanical properties of materials, especially in the plasticity, toughness, strength. Based on its excellent performance, it has been widely applied to the situation of the complex forces and serious abrasion condition of the parts manufacturing, such as the engine crankshaft.

The main parameters of two kinds of materials are shown in table 1[8]: 
Tab.1 The main parameters of two kinds of materials

\begin{tabular}{ccccc}
\hline \multicolumn{1}{c}{ materials } & $\begin{array}{c}\text { The bending fatigue } \\
\text { limit } / \mathrm{Pa}\end{array}$ & $\begin{array}{c}\text { Modulus of } \\
\text { elasticity } / \mathrm{Pa}\end{array}$ & $\begin{array}{c}\text { Poisson's } \\
\text { ratio /u }\end{array}$ & $\begin{array}{c}\text { Density } \\
/(\mathrm{g} / \mathrm{cm} 3)\end{array}$ \\
\hline \multicolumn{1}{c}{ Structure steel } & $4.6 \mathrm{E}+8$ & $2.0 \mathrm{E}+11$ & 0.3 & 7.9 \\
\hline $\begin{array}{l}\text { Chromium as cast } \\
\text { ductile iron }\end{array}$ & $3.9 \mathrm{E}+11$ & $1.9 \mathrm{E}+11$ & 0.286 & 7.2 \\
\hline
\end{tabular}

\section{Finite element analysis of crankshaft manufactured by two kinds of materials}

\subsection{The modeling of crankshaft}

Three dimensional model of crankshaft based on the single cylinder diesel engine is established by CAD software SolidWorks(simplified design of chamfer and fine oil hole) [6] as shown in figure 1:

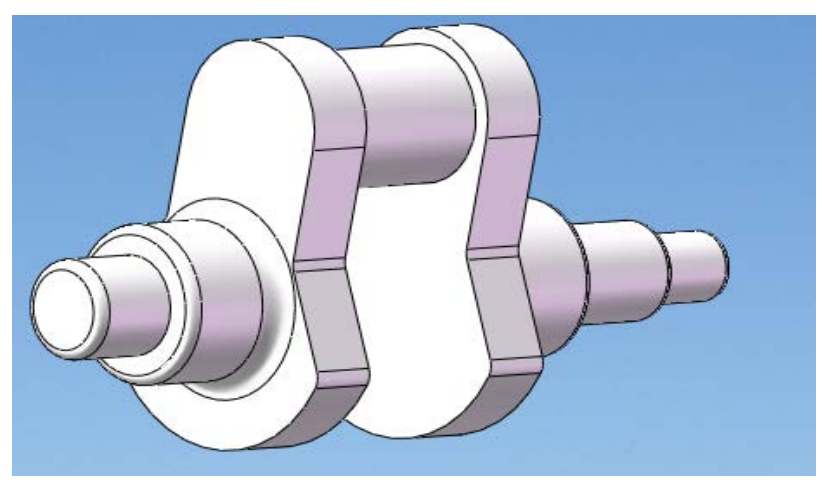

Fig.1 3D model of crankshaft(inline one cylinder)

\subsection{Crankshaft mesh}

The crankshaft solid model built in CAD software SolidWorks were imported directly into AnsysWorkbench by .prt file types. We drew the meshing on the crankshaft with 175433 nodes and 108447 elements. Length of each unit is 3mm. [5] It is shown in figure 2:

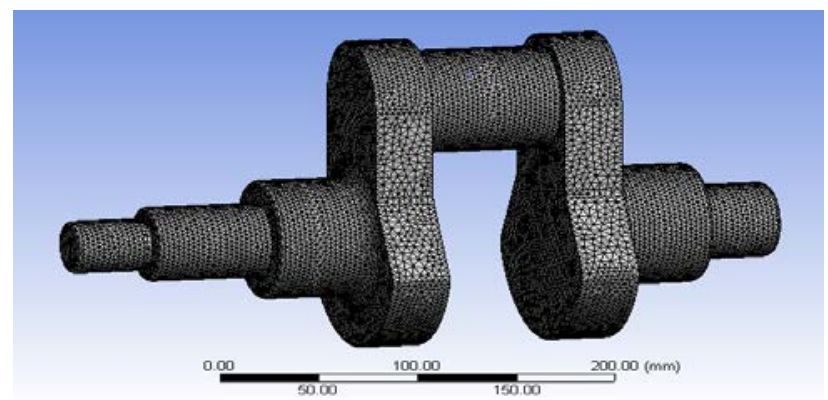

Fig.2 Finite element mesh model

\subsection{Force analysis of crankshaft under the two working conditions}

Single cylinder diesel engine is four strokes engine. Crankshaft completes a work cycle. each two turns. According to the knowledge of theoretical mechanics and mechanics of material, when the crankshaft is during the power stroke, the piston at the top dead center, which the pressure loads of crankshaft is maximum. And in the intake stroke, the piston at the top dead center, crankshaft also suffered maximum tension.[4] Two conditions of stress such as Figure 3 (a), (b) are shown[3,4]: 


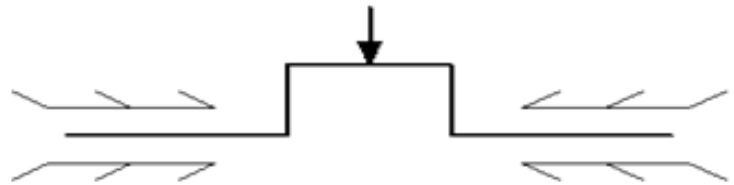

(a) compression condition

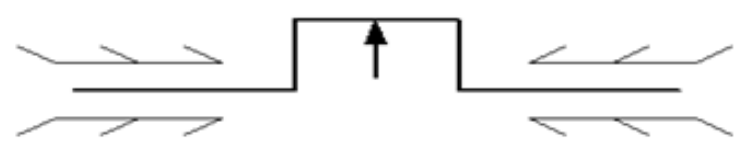

(b) tensile condition

Fig. 3 the force diagram of crankshaft

The main design dimensions of the crankshaft are as follows ${ }^{[3,4]}$ :

The crankpin radius:

Main shaft neck radius:

$$
\mathrm{r}_{1}=34.5 \mathrm{~mm}
$$

$$
\mathrm{r}=40 \mathrm{~mm} \text {; }
$$

Crank radius:

$$
\mathrm{R}=60 \mathrm{~mm} \text {; }
$$

The connecting rod big end mass center to center distance:

The connecting rod ratio:

$$
\mathrm{L}_{2}=70 \mathrm{~mm} \text {; }
$$

$$
\lambda=0.3125
$$

The total mass of connecting rod:

The total mass of piston and piston ring:

$$
\mathrm{m}_{\mathrm{r}}=2.27 \mathrm{~kg} \text {; }
$$

The connecting rod center distance:

$$
\mathrm{m}_{\mathrm{jz}}=1.76 \mathrm{~kg}
$$

Explosion pressure:

$$
\mathrm{L}=192 \mathrm{~mm} \text {; }
$$

Piston diameter:

$$
\mathrm{p}=12.5 \mathrm{MPa} \text {; }
$$

Engine calibration speed:

$$
\mathrm{D}=100 \mathrm{~mm} \text {; }
$$

$$
\mathrm{n}_{\mathrm{B}}=2200 \mathrm{rpm} \text {; }
$$

According to the practical and theoretical analysis, the bending load is the main factor that produces the damage to the crankshaft. And bending load is formed by connecting a direct effect on the crankshaft, thereby bending load is calculated as follows:[3,4]

(i) The pressure "Pg" on the crankshaft effected by the piston linkage to (downward):

$$
\mathrm{Pg}=\mathrm{p} \pi \mathrm{D}^{2} / 4=98174.76 \mathrm{~N}
$$

(ii) Reciprocating inertia force "Pr1" from connecting rod assembly, and piston reciprocating inertia force "Pr2":

$$
\begin{aligned}
& \mathrm{P}_{\mathrm{r} 1}=\mathrm{m}_{\mathrm{r}}(\mathrm{L} 2 / \mathrm{L})(1+\mathrm{R} / \mathrm{L}) \mathrm{R} \omega^{2}=3455.63 \mathrm{~N} \\
& \mathrm{P}_{\mathrm{r} 2}=\mathrm{m}_{\mathrm{jz}}(1+\mathrm{R} / \mathrm{L}) \mathrm{R} \omega^{2}=7331.94 \mathrm{~N}
\end{aligned}
$$

(iii)The connecting rod big end rotation inertia force Pr3:

$$
\mathrm{P}_{\mathrm{r} 3}=\mathrm{m}_{\mathrm{r}}\left(\mathrm{L}-\mathrm{L}_{2}\right) \mathrm{R} \omega^{2} / \mathrm{L}=4578.16 \mathrm{~N}
$$

From the above analysis, the maximum pulling force and the maximum pressure of the crankshaft appeared at the dead center, the values are showed as follows:

$$
\begin{aligned}
& \mathrm{P}_{\text {ymax }}=\mathrm{P}_{\mathrm{g}}-\mathrm{P}_{\mathrm{r} 1}-\mathrm{P}_{\mathrm{r} 2}-\mathrm{P}_{\mathrm{r} 3}=82809.03 \mathrm{~N} \\
& \mathrm{P}_{\operatorname{lmax}}=\mathrm{P}_{\mathrm{r} 1}+\mathrm{P}_{\mathrm{r} 2}+\mathrm{P}_{\mathrm{r} 3}=15365.73 \mathrm{~N}
\end{aligned}
$$

\section{4 displacement and boundary conditions}

In ANSYS analysis, it will directly affect the accuracy of the analysis whether applying of the constraints and loads is reasonable or not. Different constraints conditions and in the same load but different applied mode will make the results vary greatly. Now in accordance with the actual work conditions of crankshaft, we establish the local cylindrical coordinates in the main shaft, and 
imposed radial displacement constraint along the circumferential direction in the range of 1200 and constrained the axial displacement of the nodes on the plane of symmetry of neck connecting shaft. [2] The tensile condition constraints also make the corresponding process.

Suppose that the applying methods of maximum load under two conditions are distributed uniformly along the axis neck circle 1200 direction. As shown in figure 4[3,4]:
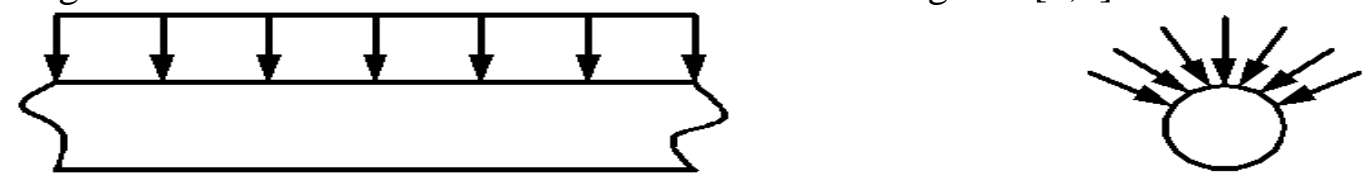

Fig.4 the force state diagram of crankshaft

\subsection{The analytical comparison of stress and strain}

Through the analytical comparison of stress and strain diagram about the crankshaft manufactured by these two kinds of materials in two different conditions, we can see: the phenomenon of stress concentration will appear in main shaft neck and crank fillet and the maximum axial stress appeared in the fillet from the followed two conditions[2,6] .Analysis results are shown in figure 5 and figure 6:

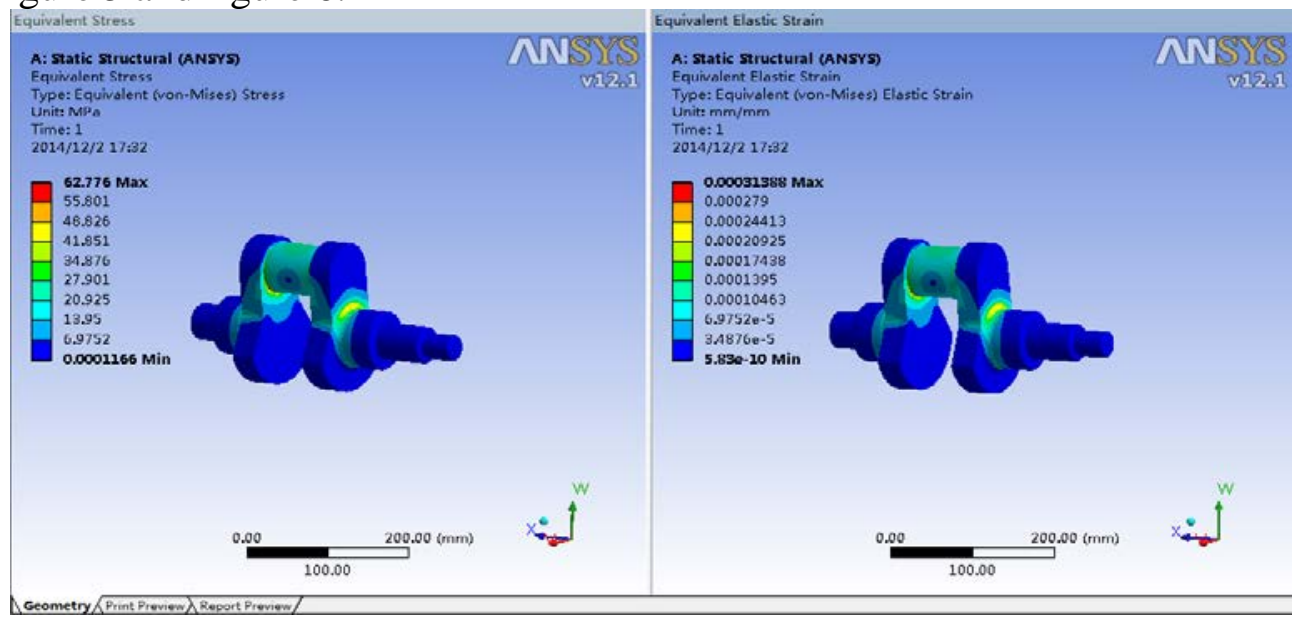

(a) stress

(b)strain

Fig. 5 the stress and strain diagram of structural steel

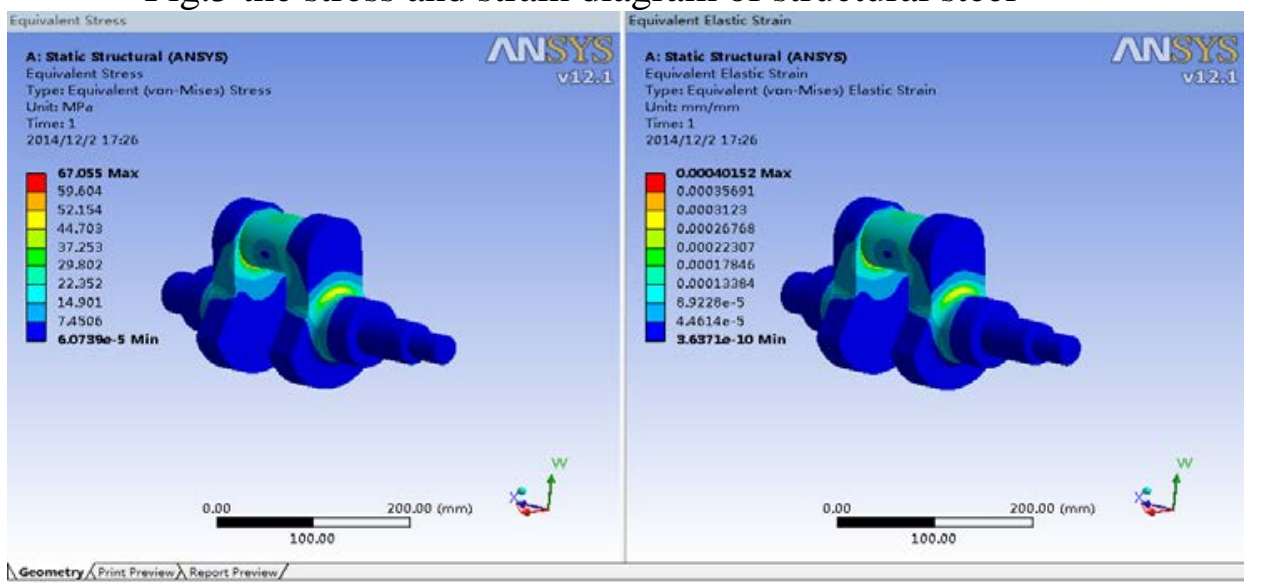

(a) stress

(b)strain

Fig6.the stress and strain diagram of nodular cast iron

\section{Conclusions}

(i) As can be seen from the graph of the crankshaft manufactured by nodular cast iron and chromium steel structure, the maximum axial stress position and stress distribution are almost the same in the two kinds of condition. So, we can draw an important conclusion that the elastic 
modulus of the material has almost no effect to the structure stress field. Different materials having divergent fatigue strength mainly depends on the material itself fatigue limits and the yield strength limits.

(ii) Thanks to the properties of nodular cast iron is closed to the carbon steel, and the nodular cast iron market price is cheaper, and more convenient, smaller density than carbon steel. Under the premise of meeting the application requirements, we should give priority to the application of nodular cast iron to manufacture crankshaft then improve economic benefit.

\section{Acknowledgements}

The research work was supported by professor Cai hanming in College of mechanical and electrical engineering of Qingdao University of Science and Technology, Qingdao 266042, China

\section{References}

[1] Sun Mingming, Hou Li.et. al. mode analysis of finite element on a crankshaft by using APDL languageto set up Three dimensional mode[J],Machinery Design \& Manufacture,2007,(1):3-5

[2] MaXun, Zuo Yuanhua, The fatigue and modal analysis of the crankshaft[J]. Research and development of vehicle,2003,(5):23-26.

[3] Gao Yunquan, Li Guifen, et al. Research on APDL entity modeling and optimization design of crankshaft[J]. Internal Combustion Engine \& power Plant, 2009, (6): 21 24.

[4] Huang Zhen, Zhang Jichun. On finite element Analysis and optimum design of crankshaft [J].Journal of Kunming University of Science and Technology (Science and Technology), 2006,31(8):94 104.

[5] Liu Birong,Stress analysis of small diesel machine based on ANSYS[J]. Tractors and farm transport vehicle,2004,04

[6] Ma Jianhui, Guo Peng .et. The finite element analysis of diesel engine crankshaft [j]. Journal of Agricultural Machine \& Chemistry,2013,(5):69-72.

[7] Liu Hongwen. Dynamics of materials [M]. Beijing: Higher Education Press.2000

[8] Zhu Zhangxiao materials of engineering [M]. Beijing: Peking Press. 2001. 